\title{
Distribution of Benthic Macrofauna Associations in the Bristol Channel in Relation to Tidal Stress
}

\author{
R. M. Warwick and R. J. Uncles
}

Natural Environment Research Council, Institute for Marine Environmental Research, Prospect Place, The Hoe, Plymouth, England

\begin{abstract}
Sediment bed types and benthic faunal associations in the Bristol Channel, U.K., are shown to be directly related to the tidally averaged $M_{2}$ bed stress as determined from a hydrodynamical numerical model. The correlation provides an important preliminary to an understanding of the physical control of community structure and function.
\end{abstract}

\section{INTRODUCTION}

Benthic macrofaunal communities have, since the classical work of Petersen (1913), been related to substrate type and sometimes designated by the type of bottom they inhabit (Jones, 1950). In shelf waters it is now recognized that, within a particular habitat type, biological interactions result in spatial and temporal heterogeneity, even on soft bottoms where 'bioturbation' plays an important role in the structuring and functioning of communities (Rhoads, 1974). However, it is equally recognized that the fundamental differences between the composition of benthic communities of broadly differing habitats (for example, mud, sand and rock) are determined physically, and that biotic interactions are of minor significance (Lindroth, 1935; Jones, 1950).

Correlations between sediment type and faunal community have usually only considered the static pattern of sediment granulometry, and not the dynamic physical environment in which the animals live. Tidal currents determine to a large degree the nature of the bottom substrate but, in addition, they influence the stability of the sediment, the nature of the food supply for benthic organisms (Wildish, 1977; Wildish and Kristmanson, 1979) and, in extreme cases, they may impose direct physical stresses on epifaunal communities. All these factors select for benthic organisms with particular morphological, physiological and behavioural adaptations. The present quantitative investigation of the effects of tidal stress on community composition and distribution is a preliminary step towards understanding further the physical imposi- tions on the biology of the benthic system. From the more utilitarian point of view, if a correlation exists between community type and tidal stress, this opens the possibility of predicting their distributions from hydrodynamical models, and perhaps anticipating changes in such distribution patterns which would result from modifications to the hydrodynamics.

The importance of tidal currents in effecting sorting and transport of sediment on the north-west European shelf has been emphasized by Stride $(1963,1965)$; tidal currents also determine the development of patterns of sedimentary bed forms, and these can be used to assess the paths of sediment transport (Stride, 1973). Generally, areas of scour on the shelf are found to correspond to regions of strongest tidal flow, and, because these regions do not coincide with areas of maximal surface wave energy, it can be assumed that tidal scour is mainly responsible for the removal of unconsolidated sediment (as bed-load) from these zones of erosion to regions having lower tidal currents.

Adjacent to the zones of erosion are areas of gravel cover which develop ribbons oriented parallel to the tidal currents (Kenyon, 1970), and which are themselves adjacent to regions of lesser currents typified by thin sand ribbons, usually overlying a horizontal gravel bed, and which are also oriented parallel to the tidal currents. In slower currents, but still within the region of sediment transport, the sand ribbons are succeeded by more rhythmically developed sand waves, with crests aligned at right angles to the tidal currents; and beyond the zones of sand transport, at still slower currents, are sheets of sand, muddy sand and mud which are, on the large-scale, featureless or 
smooth, and are due to deposition directly upon the sea bed.

Although these effects of tidal stress on the redistribution of mobile sediments have been recognized for some time, their consequences for the distributions of bottom fauna communities remain largely unexplored, at least quantitatively. The aim of this paper is to present a quantitative analysis of bed type and faunal type as functions of tidal stress at the sea bed as determined from a hydrodynamical numerical model of the Bristol Channel, a large, partially enclosed, vertically well-mixed body of water in the southwest of the British Isles.

\section{BRISTOL CHANNEL SUBSTRATE}

The Bristol Channel substrate has been described previously by Warwick and Davies (1977), and is summarised in Figure 1, where the distribution of bed types in the central part of the channel is based on side-scan sonograms, obtained by the NERC Institute of Oceanographic Sciences, and information for the bays is derived from Admiralty charts of the area. Briefly, Figure 1 shows that the inner part of the channel is a zone of erosion with a rock bed; gravel accumulates in the lower current region seaward of this zone, and may often form gravel ribbons (Type A of Kenyon, 1970), although these ribbons may occur patchily over the whole zone (only the major areas being shown in Fig. 1). The central part of the channel is a region of large sand waves, which is separated from the gravel and rock beds to the east by thin sand ribbons usually overlying a gravel floor (Type B of Kenyon, 1970), and which adjoins regions of smooth sand to the north and south. At the seaward boundary, zones of erosion are also apparent off Caldy Island and, as a continuous band, between the headland (Hartland Point) and Lundy Island.

In the eastern Bristol Channel, the bed types of Bridgwater Bay and the upper Severn Estuary are governed by conditions not considered by Stride (1963, 1965,1973 ) or Kenyon (1970), and are dependent on the extremely dense suspensions of particulate material maintained in the water column by the strong tidal currents. Kirby and Parker (1973) and Parker and Kirby (1977) have reported that during spring tides a water column may contain a virtually uniform distribution of suspended matter (with densities of the order of $10^{4} \mathrm{mng}$ $\mathrm{l}^{-1}$, whereas towards neap tides the suspended material tends to become stratified. At neap tides static fluid mud layers, typically a few metres thick with densities of the order of $5 \times 10^{4} \mathrm{mg} \mathrm{l}^{-1}$, form near the sea bed. These layers exist beneath the water column with its normal mobile suspended load of roughly $10^{4} \mathrm{mg} \mathrm{l}^{-1}$ (Kirby and Parker, 1977); although the transient fluid mud layers cannot be considered a true substrate, they must nevertheless have a profound influence on the benthic fauna, and must be considered ecologically as a distinct regime.

\section{BRISTOL CHANNEL BENTHIC COMMUNITIES}

Analysis of bottom samples from a grid of 153 stations in the Bristol Channel (Fig. 1 of Warwick and

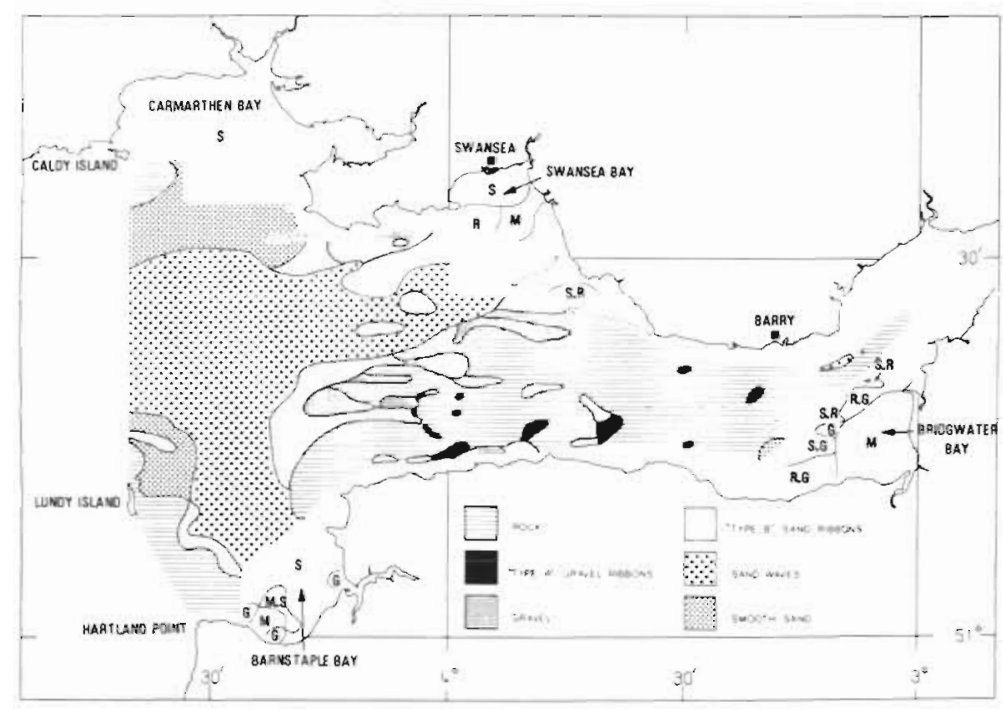

Fig. 1. Distribution of sediment bed types in Bristol Channel and western Severn Estuary. Data based on side-scan sonograms in central parts of the channel, and on Admiralty Charts in the bays. R: rock, G: gravel, S: sand, M: mud. Broken lines: positions of linear sand banks 
Davies, 1977) has provided a description of the distribution of the macrofaunal communities (Fig. 2). An objective classification of stations, based on faunal attributes, recognized subgroupings within each major community which have quite closely defined substrate preferences. The Venus community takes two forms: a Tellina subcommunity associated with the fine stable sands of Carmarthen Bay, Barnstaple Bay and the eastern part of Swansea Bay, and a Spisula subcommunity associated with the mobile areas of coarser sand (sand wave zone) in the central area of the outer channel. The Abra community takes three forms: one associated with pure mud or sandy mud bottoms in the central part of Swansea Bay and innermost part of Barnstaple Bay, one associated with a large area of smooth muddy sand off the mouth of Carmarthen Bay and the last associated with the mixed fine and coarse bottoms of the gravel and sand ribbon areas fringing the midchannel Venus community. The Modiolus community in its pure form is found on the rock floors of the central channel and other areas of strong currents, such as that between Lundy and Hartland Point and, with varying admixtures of soft bottom species, near the Abra and Venus areas where the bottom comprises mixtures of pebbles, gravel and shells with some finer sediment. Further up-channel the strong tidal scour results in a reduced hard bottom community, and the fluid muds of Bridgwater Bay have a very reduced soft bottom community. A description of the specific composition of these faunal associations is given elsewhere (Warwick and Davies, 1977).

\section{NUMERICAL MODEL AND TIDAL STRESS}

Kenyon (1970) has related the existence of a particular type of sand ribbon to the maximum surface currents during spring tides, using velocity data compiled by Sager (1968): Type A sand or gravel ribbons being associated with typical currents of 2.5 knots, Type B sand ribbons with typical currents of 2 knots and sand waves with currents of less than about 1.5 knots. In the Bristol Channel it is possible to extend this analysis owing to our detailed knowledge of tidal currents which has been derived from a hydrodynamical numerical model of the region developed by one of us (RJU) in conjunction with data on bed type given in Figure 1.

The hydrodynamical model uses a $43 \times 53$ lattice of $3.1 \mathrm{~km} \times 3.1 \mathrm{~km}$ squares over the region in Figure 3 in order to compute surface elevations and depth averaged currents for the $M_{2}$ (principal lunar semi-diurnal) tide, together with the associated quadratic stresses at the sea bed. As an illustration of how well the lattice represents the region, the discrete representation of coastal boundaries is shown in Figure 3. For most of the region the currents at a point are predominantly parallel or antiparallel to a given straight line, with magnitude $\bar{U}$ (the overbar denoting a depth average), so that the magnitude of the instantaneous frictional stress is approximately:

$$
\tau=\mathrm{p} k \bar{U}^{2}
$$

where $\mathrm{p}$ is the density of seawater and $k$ the friction parameter, with $\mathrm{p} \cong 1.03 \mathrm{~g} \mathrm{~cm}^{-3}$ and $k=2.5 \times 10^{-3}$

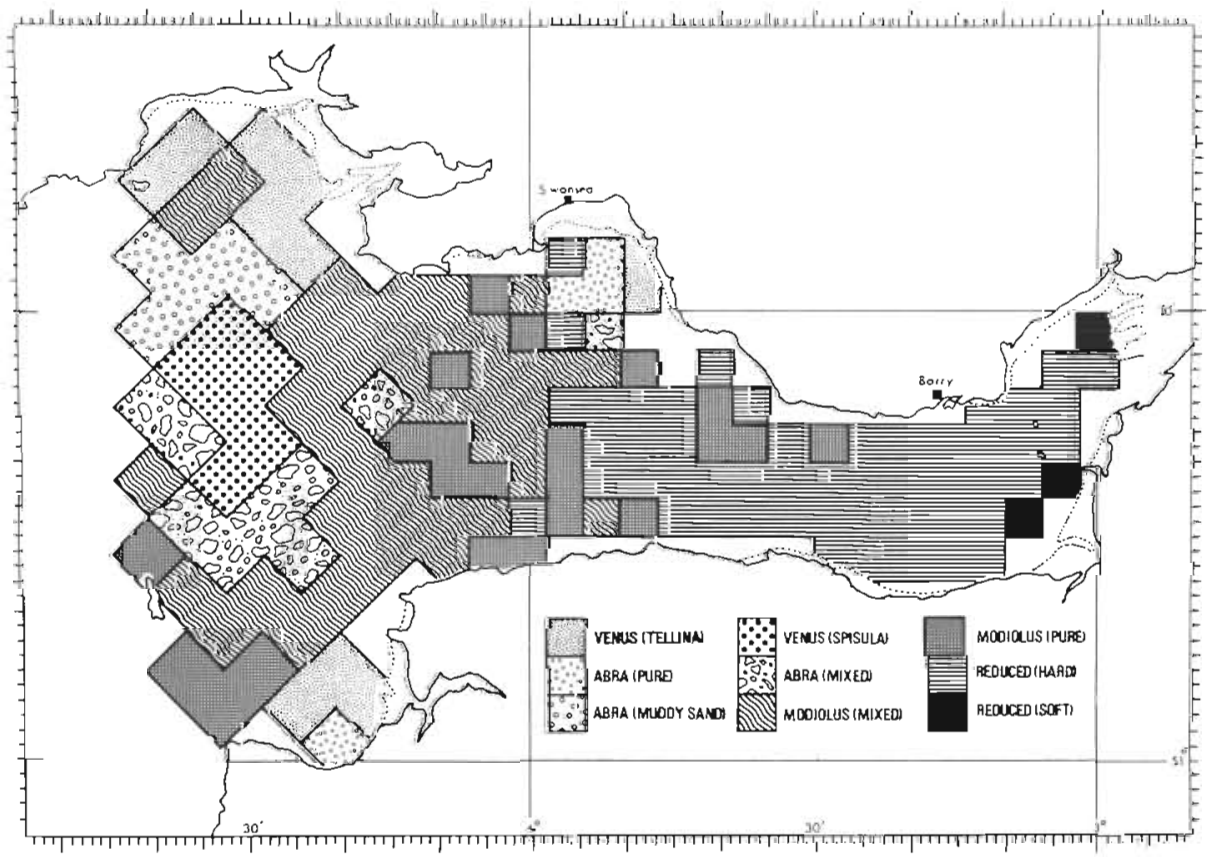

Fig. 2. Distribution of faunal associations in Bristol Channel, based on the chart of Warwick and Davies (1977) but showing major subdivisions of each community 
(Proudman, 1953). Data in Sternberg (1968) indicate that the friction parameter should vary somewhat with sediment type, although the statistical significance of this observed variation is marginal; therefore, in absence of more detailed knowledge of the relationship between friction and sediment type, a constant value of $k$ is used. Also, $\bar{U}$ is essentially sinusoidal with amplitude $\bar{U}_{\max }$ (maximum flood or ebb current for $M_{2}$ tides). Thus, the maximum stress at the sea bed during $M_{2}$ tides is, from Equation (1), approximately:

$$
\tau_{\max }=\mathrm{p} k \bar{U}^{2}{ }_{\max }
$$

and the tidally averaged $(<\cdot\rangle)$ stress for $M_{2}$ tides is approximately:

$$
<\tau>=\mathrm{p} k<\bar{U}^{2}>=1 / 2 \mathrm{p} k \bar{U}_{\text {max }}^{2}
$$

so that:

$$
\tau_{\max }=2<\tau>
$$

It follows that the maximum stresses during $M_{2}$ tides can be estimated by multiplying the contour values given in Figure 3 by a factor of 2 .

It has been shown from current measurements (by R. J. U. and M. B. Jordan of this laboratory) that the spring and neap tidal currents in the region have very nearly the same orientation and the $S_{2}$ (solar semi-diurnal) tidal currents are, on average, $36 \%$ of the magnitude of the $M_{2}$ tidal currents; the mean spring currents, $\bar{U}^{*}$, are therefore 1.36 times the $M_{2}$ currents, so that:

$$
\bar{U}_{\max }=1.36 \bar{U}_{\max }
$$

and at mean spring tides the maximum stresses are, from equations (2), (4) and (5), approximately:

$$
\left.\tau^{*}{ }_{\max }=2\left\langle\tau^{*}\right\rangle=1.8 \tau_{\max }=3.7<\tau\right\rangle
$$

from which it follows that the maximum stresses at mean spring tides are approximately 3.7 times those shown in Figure 3.

Finally, it is useful to relate the depth averaged currents computed from the model to the surface streams, $U_{s}$, since many studies of sediment movement appear to use this measure; this can be achieved by applying Van Veen's (1938) profile for the maximum tidal current:

$$
U_{\max }=U_{s, \max } \cdot(z / h)^{0.19}
$$

where $z$ is the height above the sea bed and $h$ the depth of water; from equation (7) it follows that:

$$
U_{s, \max }=1.19 \bar{U}_{\max }
$$

and at spring tides, using Equations (5) and (8):

$$
\bar{U} \cdot{ }_{s, \max }=1.19 \bar{U} \cdot{ }_{\max }=1.6 \bar{U}_{\max }
$$

None of the relationships given in Equations (1) to (9) is exact; however, the comparisons of bed and community types with tidal stress use precise values of the stress derived from modelled currents, and Equations (1) to (9) are used only to provide estimates of the stresses for conditions other than those modelled and estimates of the depth averaged and surface currents.

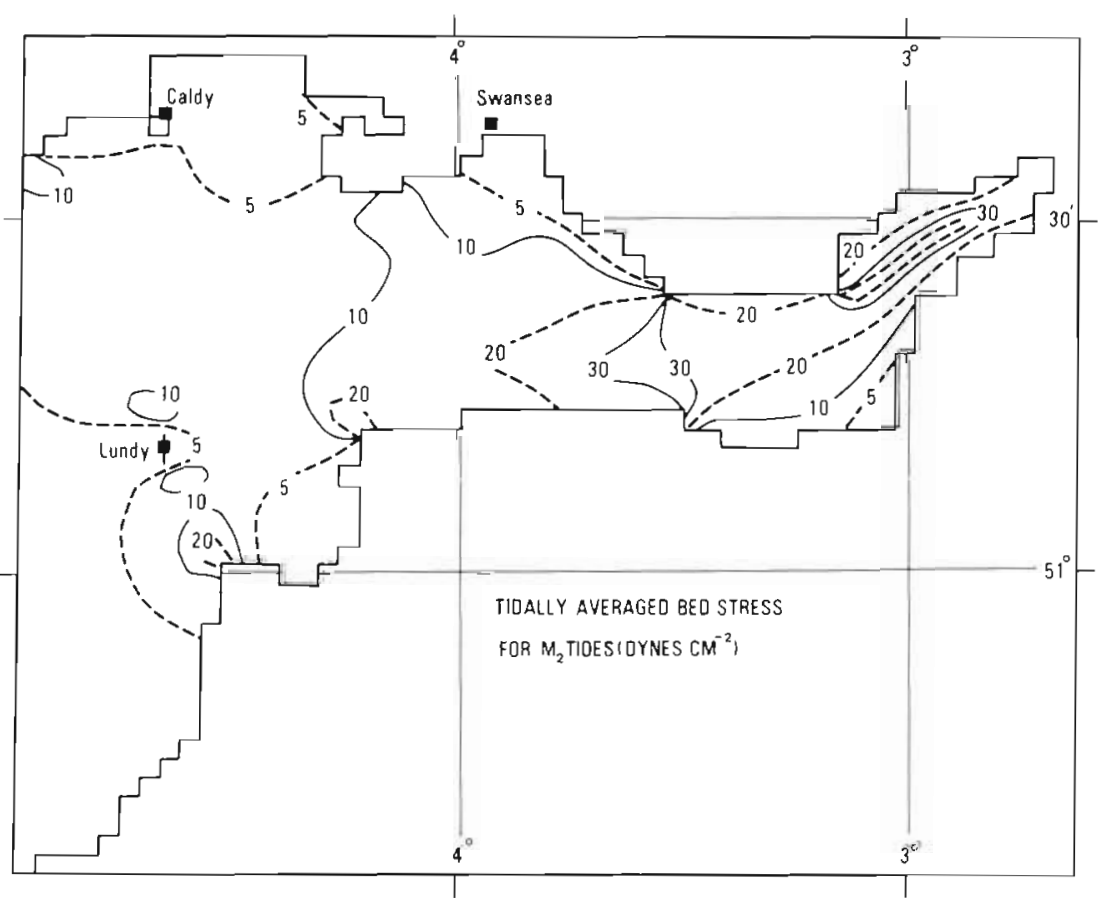

Fig. 3. Tidally averaged magnitude of sea bed stress in dynes $\mathrm{cm}^{-2}$ for $M_{2}$ tides in Bristol Channel. Data presented for the whole region modelled; discrete representation of coastal boundaries shown in order to indicate the extent to which the lattice is able to approximate the topography of the area 


\section{COMPARISON OF TIDAL STRESS WITH BED TYPE}

Data for tidal stress from Figure 3 and bed type from Figure 1 are compared for each $3.1 \mathrm{~km} \times 3.1 \mathrm{~km}$ square of the numerical model; the results are summarized in Figure 4(a) in which the mean tidally averaged stress for $M_{2}$ tides ( $<\tau>$ ), and its standard error, is plotted against bed type. Also shown are the number of data points used to derive the mean and standard error, and the values of $\bar{U}_{\max }$ corresponding to $\langle\tau\rangle$, as derived from Equation (3). The bed types were recognized from side-scan sonar. Data are not plotted for Bridgwater Bay because of the anomalous physical and ecological regimes resulting from the presence of fluid mud.

Figure 4(a) shows that the qualitative dependence of bed type on tidal stress in the Bristol Channel is similar to that proposed by Stride $(1963,1965)$ for the whole of the north-west European shelf; with the exception of the rock bed type and Type A gravel ribbons, the standard errors show that each bed type is associated with a distinct mean stress - the overlap for rock and gravel ribbons being a consequence of the patchiness of the gravel ribbons, the gravel accumulating in strike hollows in the rock, which then serve as source points for the ribbons. The standard deviations are much larger than the standard errors, and show that the overlap between bed types is considerable, as one would expect, because the presence of a particular bed type depends not only on tidal stress, but also on grain size, availability of sediment and, to some degree, the water depth and proximity to the coastal surf zone (through the influence of surface waves).

Using Equation (9), in conjunction with the values of $\bar{U}_{\max }$ plotted in Figure 4 , it is possible to assign typical maximum surface spring tide currents for each bed type, in order to compare our results with those given by Kenyon (1970); this yields 4 knots $\left(2 \mathrm{~m} \mathrm{~s}^{-1}\right.$ ) for Type A gravel ribbons (compared with a value of 2.5 knots given by Kenyon), 3 knots $\left(1.5 \mathrm{~m} \mathrm{~s}^{-1}\right)$ for Type B sand ribbons (compared with 2 knots), reducing to 2.5 knots $\left(1.3 \mathrm{~m} \mathrm{~s}^{-1}\right)$ for sand waves (compared with 1.5 knots). Typical values for the Bristol Channel are therefore about 1 knot $\left(0.5 \mathrm{~m} \mathrm{~s}^{-1}\right)$ higher than those considered to be typical for the shelf seas to the south-west of England; this implies that the grain size for each bed type in the Bristol Channel is larger than that for the corresponding type on the shelf.

\section{COMPARISON OF TIDAL STRESS WITH COMMUNITY TYPE}

In Figure 4(b) values of the tidally averaged $M_{2}$ bed stress at each benthic sampling station derived from the $43 \times 53$ lattice are plotted for each macrofaunal association. This figure shows that each community subdivision has its centre of distribution at a particular bed stress value, the means varying from 2 dynes $\mathrm{cm}^{-2}$

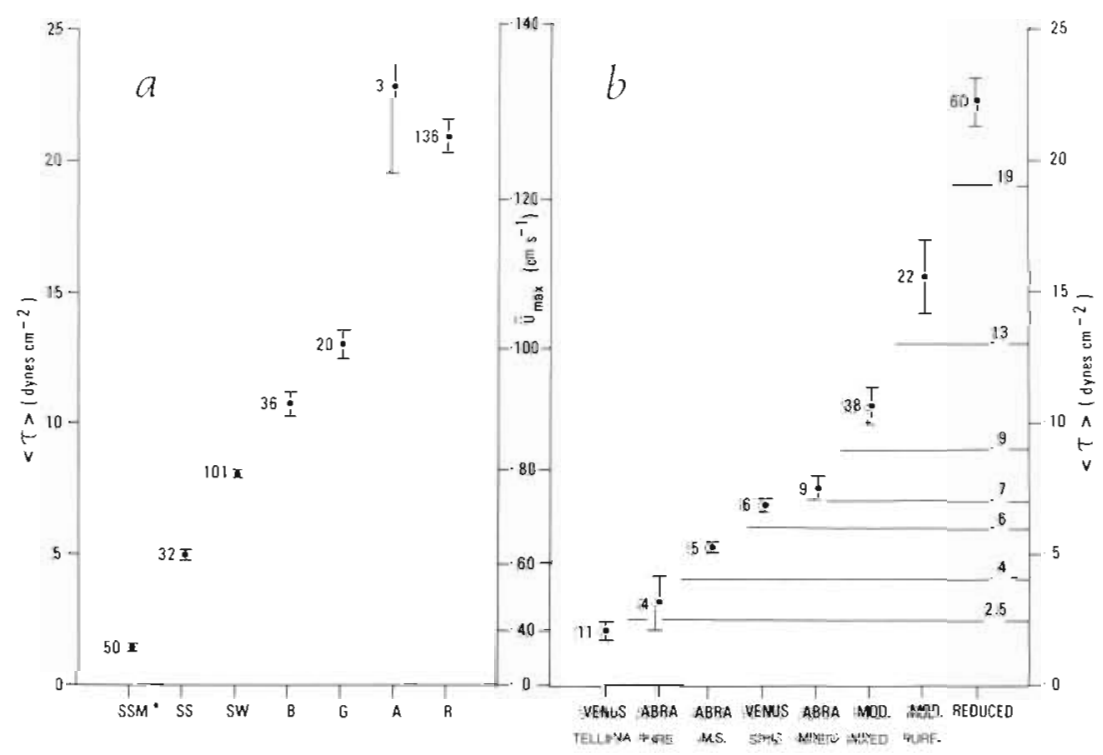

Fig. 4. Bed types and faunal types as functions of both tidally averaged sea bed stress, $\langle\tau\rangle$, for $M_{2}$ tides, and associated maximum depth averaged $M_{2}$ current speeds, $\bar{U}_{\text {max }}$. Plotted values: means and standard errors of stresses over regions associated with a particular bed or faunal type. Also shown are number of data points used to estimate means and standard errors. $4 \mathrm{a}$ : Bed type; R: rock, A: Type A gravel ribbons, G: smooth gravel, B: Type B sand ribbons, SW: sand waves, SS: smooth sand, SSM•: smooth sand or mud for the bays. $4 \mathrm{~b}$ : Faunal type; horizontal lines: values of bed stress which ideally separate faunal associations 
for the stable Venus communities of the outer bays to 22 dynes $\mathrm{cm}^{-2}$ for reduced communities in the upper part of the channel. Bed stress values mid-way between the means for each fauna type are indicated on Figure 4(b); these values, which serve as separations of faunal types, are plotted as contours in Figure 5. This figure may be considered as an idealised simulation of faunal distributions assuming that they relate directly to tidal stress with no overlap between them, and is in remarkably good agreement with the observed distributions shown in Figure 2. Figure 5 shows finer detail than is evident from the observed distributions, which were based on a coarser grid but, in cases where additional information about the fauna is available, there is good agreement in this detail, for example, the relative distributions of Venus (Tellina) and Abra (pure) communities in Swansea Bay. Other details, for example the narrow bands of Abra (pure) community bordering the Venus (Tellina) communities of Carmarthen and Barnstaple Bays, may have escaped observation.

The relationship breaks down in the fluid mud regions of the Severn Estuary, where the predicted Modiolus community is replaced by the Reduced Soft Bottom community. In these regions the suspended particulate load in the water is always exceptionally high, so that where current speeds are slightly reduced fluid mud develops, as discussed earlier; we suggest, therefore, that the empirical relationship between community type and bed stress should not be used where the secchi-disc depth is less than about $0.5 \mathrm{~m}$.

\section{DISCUSSION}

Although we have, for the first time, established a direct correlation between faunal type and tidal stress, the underlying causes for this relationship require further examination. At high current speeds the reduction in species between the Modiolus and Reduced Hard Bottom communities is undoubtedly related to the relative abilities of species to maintain a foothold, by the use of various adhesive and behavioural mechanisms at very high levels of tidal stress. At lesser current speeds the differences in fauna between the mobile areas of sediment transport (sand waves) and more stable areas presumably involve mechanical resistance to abrasion as well as feeding behaviour. Species in the sand wave zones tend to be robust filter feeders and those in sedimentary areas include more delicate deposit feeders. Warwick and Davies (1977) have discussed elsewhere the contrasting morphological characters of benthic species in these two areas.

The applicability of this relationship to other shallow water areas requires testing, but wherever community structure is physically controlled, the correlation is likely to hold good. In deeper water, where physical processes are of smaller magnitude, species associations are more likely to be determined by biological interactions (Sanders, 1968) and the relationship described here may not be apparent.

Acknowledgements. This work forms part of the estuarine ecology programme of the Natural Environment Research

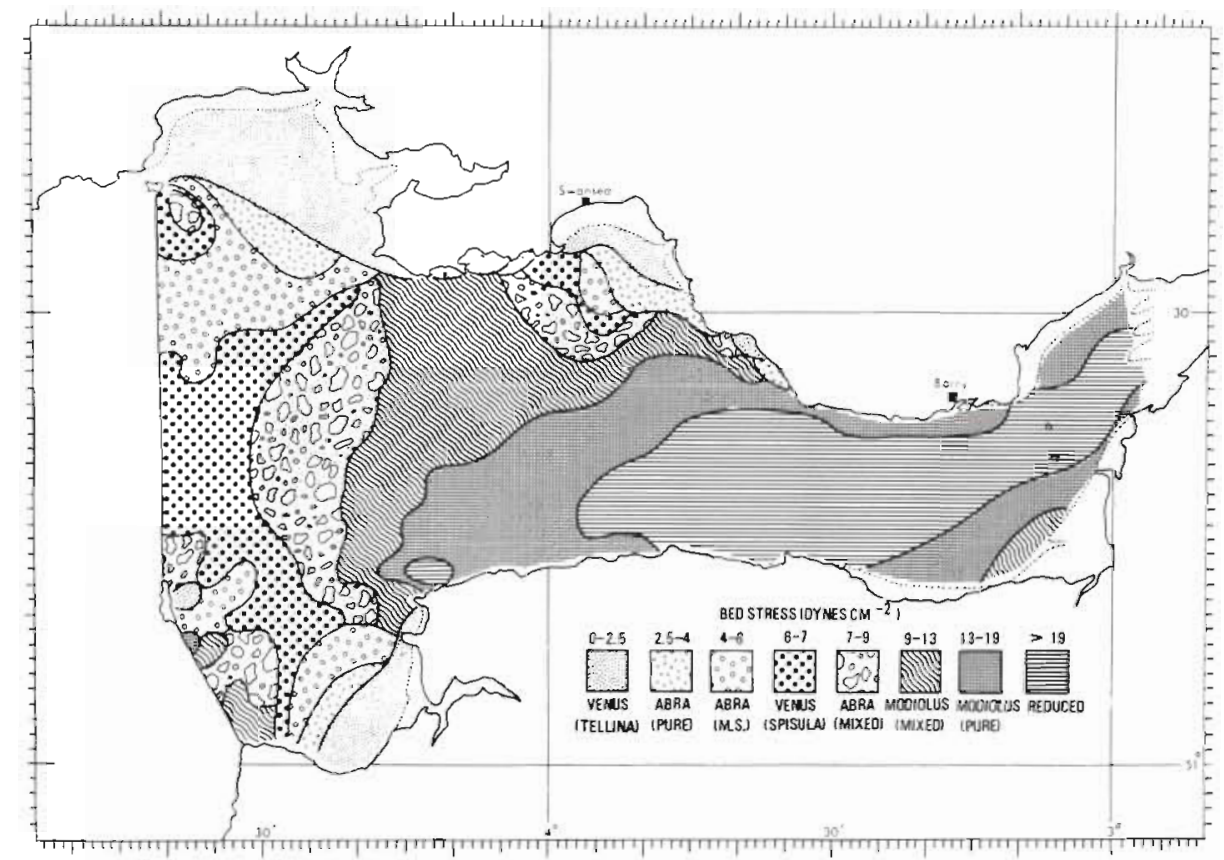

Fig. 5. Bed stress contours for Bristol Channel selected from Figure $4 b$ to delineate faunal associations 
Council, U.K., and was supported in part by funds from the Department of the Environment, under Contract No. DRG/ $480 / 48$.

\section{LITERATURE CITED}

Jones, N. S. (1950). Marine bottom communities. Biol. Rev. 25; 283-313

Kenyon, N. A. (1970). Sand ribbons of European tidal seas. Mar. Geol. 9: 25-39

Kirby, R., Parker, W R. (1973) Fluid mud in the Severn Estuary and Bristol Channel and its relevance to pollution studies. Inst. Chem. Eng., Grad. Stud. Sect., Ann. Symp., Est. Coastal Poll., Exeter, 27-28/9/73

Kirby, R., Parker, W. R. (1977). Sediment dynamics in the Severn estuary: a background for studies of the effects of a barrage. In: Shaw, T. L. (ed.) An environmental appraisal of the Severn Barrage. Dep. Civ. Engineering, University of Bristol, pp. 41-52

Lindroth, A. (1935). Die Associationen der marinen Weichböden. Zool. Bidr. Uppsala 15: 331-366

Parker, W. R., Kirby, R. (1977). Vertical concentration profiles in estuarine fine sediment suspensions. Euromech 95, Symp. Univ. College Swansea 13-15/9/77

Petersen, C. G. J. (1913). Valuation of the sea II. The animal communities of the sea bottom and their importance for marine zoogeography, Rep. Dan. biol. Stn 21: 1-44

Proudman, J. (1953) Dynamical oceanography, Methuen, London
Rhoads, D. C. (1974). Organism-sediment relations on the muddy sea floor Oceanogr Mar. Biol. Ann. Rev. 12: 263-300

Sanders, H. L. (1968). Marine benthic diversity: a comparative study. Am. Nat. 102: 243-282

Sager, G. Von. (1968). Atlas der Gezeitenströme für die Nordsee, den Kanal und die Irische See. Institut für Meereskunde, Rostock

Sternberg, R. W. (1968). Friction factors in tidal channels with differing bed roughness. Mar. Geol. 6: 243-260

Stride, A. H. (1963) Current - swept sea floors near the southern half of Great Britan. Q. Jl geol. Soc. Lond. 119: 175-199

Stride, A. H. (1965). Marine geology at the N.I.O. The Times Sci, Rev. 58: 10-11

Stride, A. H. (1973). Sediment transport by the North Sea. In: Goldberg, E. D. (ed.) North Sea science, M.I.T. Press, Cambridge, Mass., pp. 101-130

Van Veen, J. (1938). Water movements in the Straits of Dover. J. Cons. int. Explor. Mer 13; 7-36

Warwick, R. M., Davies, J. R. (1977). The distribution of sublittoral macrofauna communities in the Bristol Channel in relation to the substrate. Estuar \& Coast. Mar. Sci. 5: $267-288$

Wildish, D. J. (1977). Factors controlling marine and estuarine sublittoral macrofauna. Helgoländer wiss. Meeresunters. 30: $445-454$

Wildish, D. J., Kristmanson, D. D. (1979). Tidal energy and sublittoral macrobenthic animals in estuaries. J. Fish. Res. Bd Can. 36: 1197-1206

This paper was submitted to the editor; it was accepted for printing on June 9, 1980 